\title{
Watson syndrome: is it a subtype of type 1 neurofibromatosis?
}

\author{
J E Allanson, M Upadhyaya, G H Watson, M Partington, A MacKenzie, D Lahey, \\ H MacLeod, M Sarfarazi, W Broadhead, P S Harper, S M Huson
}

\begin{abstract}
Over 20 years ago, Watson described three families with a condition characterised by pulmonary valvular stenosis, café au lait patches, and dull intelligence. Short stature is an additional feature of this autosomal dominant condition. A fourth family with Watson syndrome has since been reported. We have had the opportunity to review members of three of these four families. The clinical phenotype of Watson syndrome has been expanded to include relative macrocephaly and Lisch nodules in the majority of affected subjects, and neurofibromas in one-third of family members. Because the additional clinical findings enhance the similarity between Watson syndrome and neurofibromatosis 1, molecular linkage studies have been performed using probes flanking the NF1 gene on chromosome 17. Probe HHH202 showed the tightest linkage to Watson syndrome with a maximum lod score of 3.59 at $\theta=0.0$ (95\% confidence limits of $\theta=0 \cdot 0-0 \cdot 15$ ). This suggests either that Watson syndrome and neurofibromatosis 1 are allelic, or that there is a series of
\end{abstract}

Division of Genetics, Children's Hospital of Eastern Ontario, 401 Smyth Road, Ottawa, Ontario K1H 8L1, Canada.

J E Allanson, A MacKenzie, D Lahey, H Macleod

Institute of Medical Genetics, University Hospital of Wales, Cardiff CF4 4XN.

M Upadhyaya, M Sarfarazi, W Broadhead, P S Harper

Royal Manchester Children's Hospital, Manchester. G H Watson

Western Suburb Hospital, Newcastle, New South Wales, Australia.

M Partington

Department of Genetics, Churchill Hospital, Headington, Oxford.

$S M$ Huson

Correspondence to Dr Allanson.

Received for publication 31 January 1991.

Revised version accepted for publication 14 May 1991 contiguous genes for pulmonary stenosis, neurocutaneous anomalies, short stature, and mental retardation on $17 q$.

Watson syndrome is characterised by pulmonary valvular stenosis, café au lait (CAL) patches, dull intelligence, and short stature..$^{2}$ Four families with this autosomal dominant disorder have been reported to date. ${ }^{3}$ The clinical overlap between Noonan syndrome and Watson syndrome, plus recent reports of cases with features of type 1 neurofibromatosis (NF1) and Noonan syndrome, ${ }^{4}$ led us to re-evaluate the Watson syndrome families to review the relationship between Watson syndrome, NF1, and Noonan syndrome.

Since the initial localisation of NF1 to the pericentromeric region of chromosome $17,{ }^{56}$ rapid progress has been made in refining the genetic map of the NF1 region, culminating in recent cloning of the NF1 gene. ${ }^{7-9}$ The segregation of RFLPs closely linked to NF1 has been studied in the two largest Watson syndrome families reported (family $\mathrm{C}$ in the report of Watson ${ }^{1}$ and family D of Partington $e t a \beta^{3}$ ). The results of this analysis and of the clinical reassessment of members of three of the four Watson syndrome families are reported.

\section{Materials and methods}

Through the original authors, the families were contacted again and willing family members reassessed (in England by JEA, SMH, and GW; in Canada by JEA). Venous blood $(20 \mathrm{ml})$ was obtained from each member of the two largest families $(\mathrm{C}$ and D). DNA was extracted from lymphocyte nuclei. ${ }^{10}$ DNA $(5 \mu \mathrm{g})$ was digested with the appropriate restriction endonucleases and transferred by Southern blotting to Hybond-N (Amersham). DNA markers were labelled by primer extension ${ }^{11}$ and hybridised to the Hybond-N membrane at $65^{\circ} \mathrm{C}$. The repetitive sequences in DNA probes VAW211, VAW215, VAW210, HHH202, EW203, EW204, and EW205 were competed out with total genomic DNA $(0.5 \mathrm{mg} / \mathrm{ml})$. 
We used 18 polymorphic markers spanning the region $17 \mathrm{p} 11.1$ to $\mathrm{q} 11.2$. The physical localisation and allele frequencies for each marker have been reported earlier. ${ }^{12}{ }^{13}$ Two point linkage analysis between the markers and disease was performed using the program MLINK. Confidence intervals were calculated by the one lod unit method. ${ }^{14}$

\section{Results}

CLINICAL DATA

We were unable to contact family A of Watson. ${ }^{1}$ One or more members of the remaining families were assessed. The pedigrees are shown in the figure and the clinical features summarised in table 1 . The most important features in each family are discussed below.

Family B. II $\cdot 2$ is now a long stay patient in a centre for patients with epilepsy. $\mathrm{He}$ is otherwise in good health. On examination, he showed remarkable fading of his CAL spots and axillary freckling compared to the original photographs. There were only seven CAL spots $>1.5 \mathrm{~cm}$ diameter compared to 13 at the time of original assessment. There were no neurofibromas, but approximately 20 Lisch nodules were seen in each iris.

Family $C$. This family was extensively reassessed and the next generation was examined. CAL patches were universal, axillary freckling was extremely common, and borderline or reduced intellectual functioning was frequently seen. Pulmonary valvular stenosis was present in five family members, all of whom were in the second generation. Pulmonary atresia was the cause of death in the first member of the third generation; CAL spots had not been noted in this young girl by the family or hospital staff. Short stature was seen in two-thirds of affected subjects. Two new clinical features, which were not present in the original description of this family, are of particular importance when we compare Watson syndrome to NF1. Lisch nodules were seen in seven subjects. Neurofibromas were noted in three family members, although they were present in very small numbers. Histological confirmation of this diagnosis
(A)

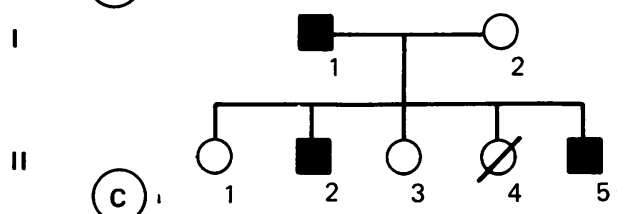

(B)

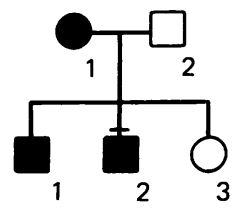

I

II

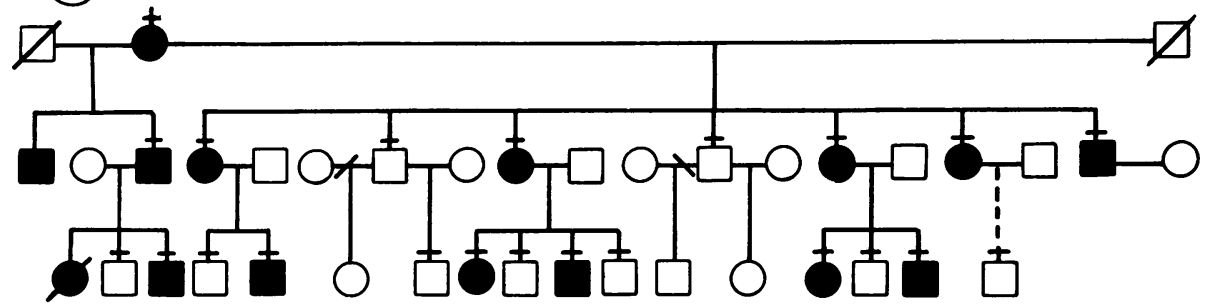

।

(D)

II

III

IV

v

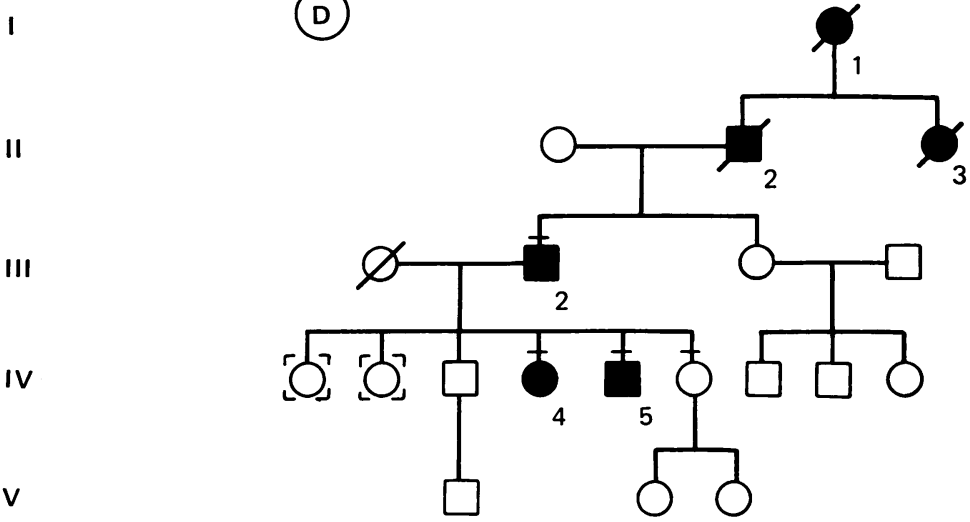

Pedigrees of the four families. 


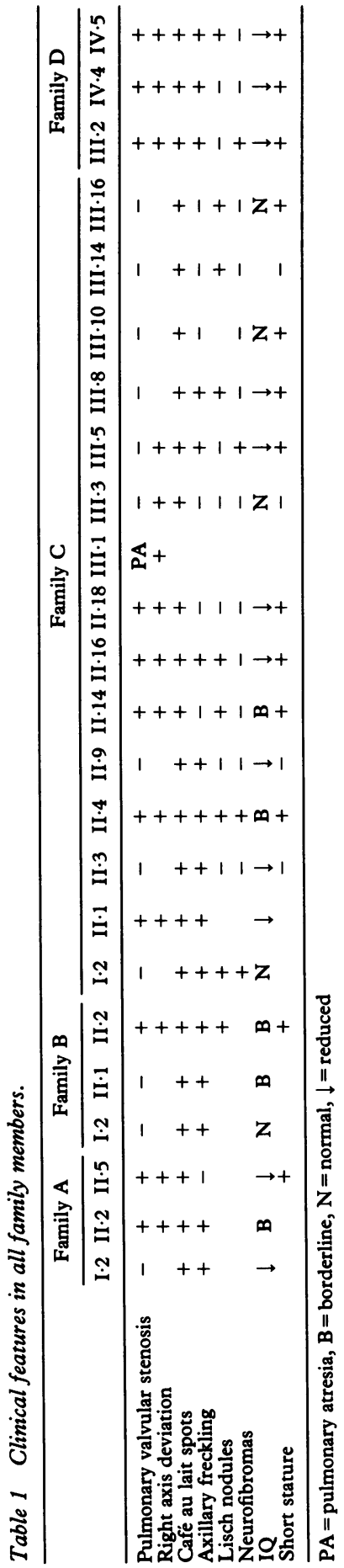

was obtained in at least one tumour from each person.

Family $D .{ }^{3}$ Three living family members (III-2, IV.4, IV.5) had pulmonary valvular stenosis with right axis deviation, CAL patches with axillary freckling, low IQ, and short stature. In addition, the youngest of the three (IV.5) had Lisch nodules, and the father (III.2) had multiple neurofibromas over his trunk and arms.

\section{GENETIC LINKAGE DATA}

Of the 18 markers studied in family C, eight (pA1041, pTH17·19, VAW211, VAW215, EW206, C11·7, EW203, and EW205) were not informative. Two point linkage between $N F 1$ and each marker is summarised in table 2. DNA marker HHH202 is closely linked with a lod score of 3.29 at $\theta=0.00$. The lod score for other markers is lower but positive. Affected subjects have also been analysed using gene specific markers EE3.8, EE14, and P5. ${ }^{8}$ No abnormality has been detected.

Molecular studies in family D confirm linkage to HHH202. Combined data, also presented in table 2, indicate that $\mathrm{HHH} 202$ shows tightest linkage to Watson syndrome with a maximum lod score of 3.59 at $\theta=0.0$ ( $95 \%$ confidence limits of $\theta=0.0$ to 0.15$)$.

\section{Discussion}

The cardinal features of Watson syndrome are pulmonary valvular stenosis, café au lait spots, dull intelligence, and short stature. We have described two new features: Lisch nodules are present in $58 \%$ of those examined with a slit lamp, and neurofibromas are noted in one-third of all family members. This has markedly increased the similarity between Watson syndrome and NF1.

From a clinical viewpoint, the finding of Lisch nodules and neurofibromas in some subjects with Watson syndrome raises the question of whether this is a unique syndrome. All of the reported affected subjects would satisfy the NIH diagnostic criteria for NF $1 .{ }^{15}$ However, the frequency of associated features is atypical, and the lack of NF1 complications, other than dull intelligence and short stature, would be unusual in a cohort of this size..$^{16} \mathrm{~A}$ comparison between Watson syndrome and NF1 is seen in table 3.

The major features defining NF1 are CAL spots (with or without freckling in the axillae and other characteristic areas), dermal neurofibromas, and Lisch nodules. In Watson syndrome families, only the pigmentary changes occur in a similar frequency to that seen in NF1. Indeed, although there have been subjective reports of disappearance of CAL spots with age in NF1, 16 the subject in family B (II.2) is the first case with objective confirmation of 
this phenomenon. The frequency of both Lisch nodules and neurofibromas is highly atypical compared to that reported in other large series. ${ }^{16} 18$ Huson $e t a^{16}$ noted that all subjects with NF1, over 20 years old, had neurofibromas, and the majority had more than 10 in number. In the present families, neurofibromas are only present in four subjects over 20 , and only two patients have more than 10 neurofibromas (family C III $\cdot 5$, family D III.2). Lisch nodules are present in $93 \%$ of subjects with NF1 compared to $58 \%$ in Watson syndrome.

The minor features of NF1, macrocephaly and short stature, also show an unusual distribution in Watson syndrome. Absolute macrocephaly is present in $45 \%$ of patients with NF $1^{16}$ but is uncommon in Watson syndrome, although relative macrocephaly is seen in more than $50 \%$ of these subjects. Short stature is observed in almost $80 \%$ of patients with Watson syndrome compared to $34 \%$ of those with NF1. ${ }^{16}$

The complications of NF1 are numerous, affect almost every body system, and occur at random, even within families. However, in Watson syndrome, the only other features are dull intelligence and pulmonary stenosis. Borderline or reduced intelligence is seen in $68 \%$ of subjects with Watson syndrome compared to $33 \%$ in NF1. ${ }^{19}$ Pulmonary stenosis is documented in $52 \%$ of patients with Watson syndrome, while cardiac anomalies do not occur with increased frequency among patients with NF1. 161820 There have been two reports of valvular pulmonary stenosis in NF1: five patients described by Kaufman et $a l^{21}$ and three family members reported by Neiman et al. ${ }^{22}$ The latter family has a phenotype suggestive of Watson syndrome. All three family members have mental retardation. In his original report, Watson ${ }^{1}$ provided convincing evidence against the chance occurrence of NF1 and pulmonary stenosis in three families from one paediatric cardiology practice; the reporting of an additional family would support this.

The present reappraisal has provided no evidence to suggest that Watson syndrome overlaps with Noonan syndrome. The cardiac lesions observed seem to be distinct. In Noonan syndrome, several different cardiac anomalies are described with characteristic left axis deviation, whereas in Watson syndrome only pulmonary stenosis is found, in association with right axis deviation. Watson syndrome does not seem to be associated with a particular facial 'gestalt' in contrast to the distinctive facies in Noonan syndrome. ${ }^{23}$

From our clinical studies we concluded that these families have a syndrome combining some features of NF1 with pulmonary stenosis, but the frequency of the neurocutaneous features and complications, which are so distinct from those in classical NF1, justified the designation of a unique syndrome. The availability of closely linked RFLPs for the NF1 gene $^{24}$ allowed us to investigate the relationship between NF1 and Watson syndrome at the molecular level.

Our finding of close linkage between the Watson syndrome families and a proximal chromosome 17q RFLP (table 2) could have a number of possible explanations. We feel the least likely is that Watson syndrome and NF1 are simply closely linked. More likely explanations are that Watson syndrome is allelic to NF1 or that there is a pulmonary stenosis gene contiguous to NF1..$^{25}$ The NF1 gene has been found to be extremely complex and spans at least three active genes in opposing orientation..$^{7-9}$

Table 2 Linkage analysis between Watson syndrome and chromosome 17 markers.

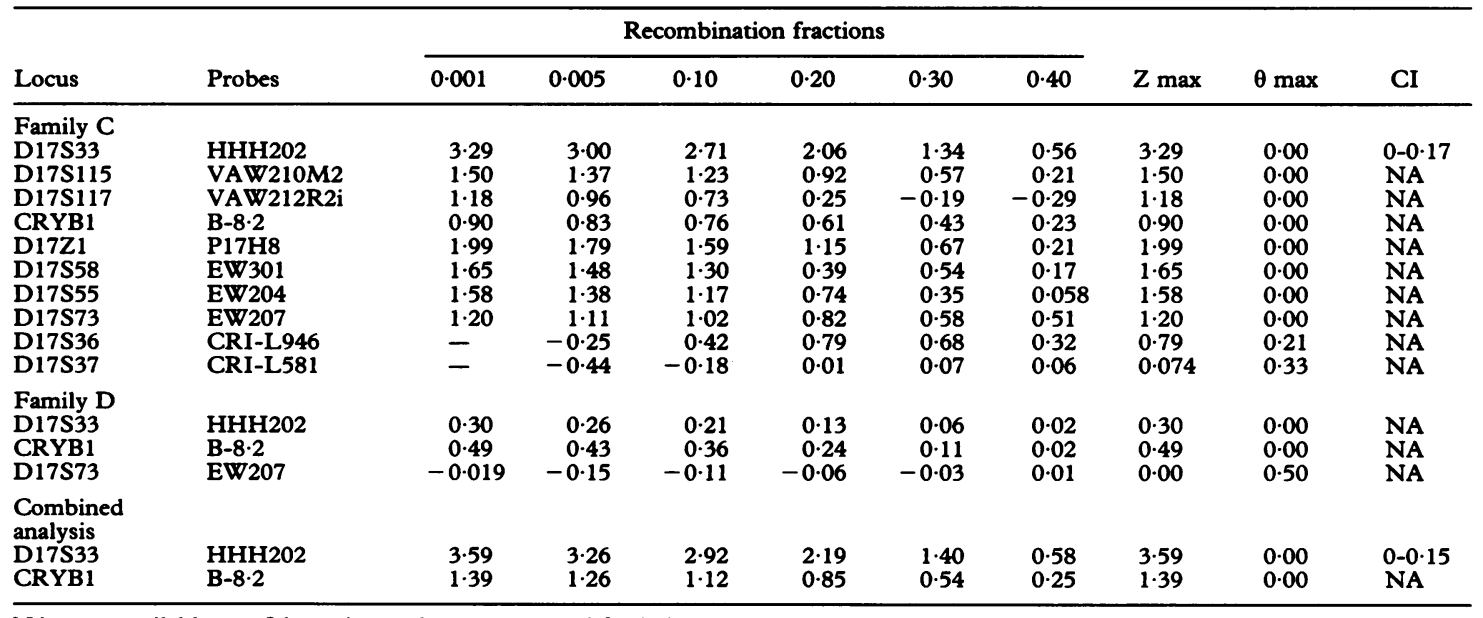

NA = not available: confidence intervals not warranted for lod scores $<3$. 
Table 3 Comparison of Watson syndrome and neurofibromatosis.

\begin{tabular}{lcc}
\hline & WS (\%) & NF (\%) \\
\hline Pulmonary valvular stenosis & 50 & Rare* \\
Café au lait patches & 100 & 100 \\
Axillary freckling & 66 & 66 \\
Lisch nodules & 58 & 93 \\
Neurofibromas & 33 & 100 \\
Reduced IQ & 68 & 25 \\
Short stature & 76 & 34 \\
\hline
\end{tabular}

*6 cases

Although mutations in any one of these three genes identified within the NF1 gene seem unlikely to cause pulmonary stenosis, there may be other genes still to be identified which could. Alternatively, one particular NF1 mutation could give rise to the Watson phenotype in some other way. Lastly, the overlapping phenotypes of Watson syndrome, NF1, and Noonan syndrome may imply a series of contiguous genes for NF1, pulmonary stenosis, lymphatic abnormalities, and perhaps also short stature and macrocephaly..$^{25}$

These hypotheses can now be tested by applying linkage analysis of NF1 markers to pure autosomal dominant pulmonary stenosis, multigenerational families with Noonan syndrome, and direct analysis of the NF1 gene in these Watson syndrome families.

We would like to thank Drs Peter Lunt, Patrick MacLeod, and Maurice Super who helped in the clinical evaluation of the families; Bernice Chisholm who typed the manuscript; and the many family members who gave generously of their time and cooperation.

1 Watson GH. Pulmonary stenosis, cafe-au-lait spots, and dull intelligence. Arch Dis Child 1967;42:303-7.

2 Allanson JE, Watson GH. Watson syndrome: nineteen years on. Proc Greenwood Genetic Center 1987;6:173.

3 Partington MW, Burggraf GW, Fay JE, Frontini E. Pulmonary stenosis, cafe-au-lait spots and dull intelligence: the Watson syndrome revisited. Proc Greenwood Genetic Center 1985;4:105.

4 Allanson JE, Hall JG, Van Allen MI. Noonan phenotype associated with neurofibromatosis. Am $\mathcal{f}$ Med Genet $1985 ; 21: 457-62$.
5 Barker D, Wright EC, Nguyen $\mathrm{K}$, et al. Gene for von Recklinghausen neurofibromatosis is in the pericentromeric region of chromosome 17. Science 1987;236:1100-2.

6 Seizinger B, Rouleau GA, Ozelius LJ, et al. Genetic linkage of von Recklinghausen neurofibromatosis to the nerve growth factor receptor gene. Cell 1987;49:589-94.

7 Cawthon RM, Weiss R, Xu G, et al. A major segment of the neurofibromatosis type 1 gene: cDNA sequence, genomic structure, and point mutations. Cell 1990;62:193-201.

8 Viskochil D, Buchberg AM, Xu G, et al. Deletions and a translocation interrupt a cloned gene at the neurofibromatosis type 1 locus. Cell 1990;62:187-92.

9 Wallace MR, Marchuk DA, Andersen LB, et al. Type 1 neurofibromatosis gene: identification of a large transcript disrupted in three NF1 patients. Science 1990;249:181-6.

10 Kunkel LM, Smith KD, Boyer SH, et al. Analysis of human Ychromosome-specific reiterated DNA in chromosome variants. Proc Natl Acad Sci USA 1977;74:1245-9.

11 Feinberg AP, Vogelstein B. A technique for radiolabelling DNA restriction fragments to a high specific activity. Anal Biochem 1984;137:266-7.

12 Fain PR, Goldgar DE, Wallace MR, et al. Refined physical and genetic mapping of the NF1 region on chromosome 17. $\mathrm{Am} \mathcal{J}$ Hum Genet 1989;45:721-8.

13 Upadhyaya M, Sarfarazi M, Huson SM, Broadhead W, Fryer A, Harper PS. Close flanking markers for neurofibromatosis type 1 (NF1). Am F Hum Genet 1989;44:41-7.

14 Conneally PM, Edwards JH, Kidd KK, et al. Report of the Committee on methods of linkage analysis and reporting. HGM8. Cytogenet Cell Genet 1985;40:356-9.

15 National Institutes of Health Consensus Development Conference. Neurofibromatosis consensus statement. Arch Neurol 1988;45:575-8.

16 Huson SM, Harper PS, Compston DAS. Von Recklinghausen neurofibromatosis: a clinical and population study in southeast Wales. Brain 1988;111:1355-81.

17 Crowe FW, Schull WJ, Neel JV. A clinical, pathological and genetic study of multiple neurofibromatosis. Springfield, Il: Charles C Thomas, 1956.

18 Riccardi VM, Eichner JE. Neurofibromatosis: phenotype, natural history, and pathogenesis. Baltimore: Johns Hopkins University Press, 1986.

19 Huson SM, Compston DAS, Harper PS. A genetic study of von Recklinghausen neurofibromatosis in south-east Wales. II. Guidelines for genetic counselling. I Med Genet 1989;26:704-21.

20 Lin AE, Garver KL. Cardiac abnormalities in neurofibromatosis. Neurofibromatosis 1988;1:146-51.

21 Kaufman RL, Hartmann AF, McAlister WH. Family studies in congenital heart disease. IV. Congenital heart disease associated with neurofibromatosis. Birth Defects 1972; VIII(5):92-5.

22 Neiman HL, Mena E, Holt JF, Stern AM, Perry BL. Neurofibromatosis and congenital heart disease. $A \mathcal{F}$ 1974;122:146-9.

23 Allanson JE, Hall JG, Hughes HE, Preus M, Witt RG. Noonan syndrome: the changing phenotype. Am $\mathcal{f}$ Med Genet 1985; 21:507-14.

24 Goldgar DE, Green P, Parry D, Mulvihill JJ. Multipoint linkage analysis in neurofibromatosis type 1: an international collaboration. Am f Hum Genet 1989;44:6-12.

25 Hall JG, Allanson JE. Neurofibromatosis 1. Predicting the relation of gene structure to gene function. $A m \mathcal{F}$ Med Genet 1991;38:135. 